\title{
FUNDAMENTALS OF QUEUEING NETWORKS: PERFORMANCE, ASYMPTOTICS AND OPTIMIZATION by Hong Chen and David D. Yao
}

\author{
A BOOK REVIEW \\ H.M. SRIVASTAVA \\ University of Victoria \\ Department of Mathematics and Statistics \\ Victoria, British Columbia V8W 3P4, Canada \\ E-mail: harimsri@math.uvic.ca
}

(Received June, 2002; Revised September, 2002)

This book has stemmed essentially from the lecture notes which were accumulated over many years of teaching of graduate-level courses on stochastic networks by the authors at the University of British Columbia (Vancouver, Canada) and Columbia University (New York, USA), respectively. Its main objective is to collect, in one single volume, the essentials of stochastic networks, right from the classical product-form theory to such more recent developments as diffusion and fluid limits, stochastic comparisons, stability, control (dynamic scheduling), and optimization.

The book consists of three parts. The first part, Chapters 1 through 4, covers (continuoustime) Markov-chain models, including the classical Jackson and Kelly networks, the notion of quasi-reversible queues, and stochastic comparisons. The second part, Chapters 5 through 10, focuses on Brownian models, including limit theorems for generalized Jackson networks and multiclass feedforward networks, an in-depth examination of stability in a KumarSeidman network, and Brownian approximations for general multiclass networks with a mixture of priority and first-in-first-out disciplines. The third part, Chapters 11 and 12, discusses scheduling in both queueing (stochastic) and fluid (deterministic) networks, along with topics such as conservation laws, polymatroid optimization, and linear programming.

Although as remarked by the authors themselves, the selection of materials for this book inevitably is a reflection upon their own bias and preference, the book under review is also driven largely by their desire to provide a graduate-level text, that is well balanced in breadth and depth, suitable for the classroom. In light of the wide-ranging applications of stochastic networks in recent years, from supply chains to telecommunications, this book is intended also to serve as a useful reference for teachers, researchers, and students alike in many of these diverse fields.

Fundamentals of Queueing Networks: Performance, Asymptotics and Optimization

by Hong Chen and David D. Yao

Publisher: Springer-Verlag

Publication Year: 2001

ISBN: 0-387-95166-0

Price: $\$ 64.95$ 


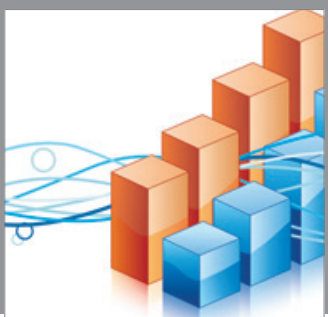

Advances in

Operations Research

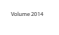

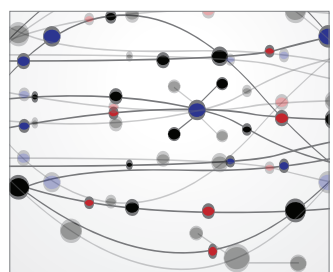

\section{The Scientific} World Journal
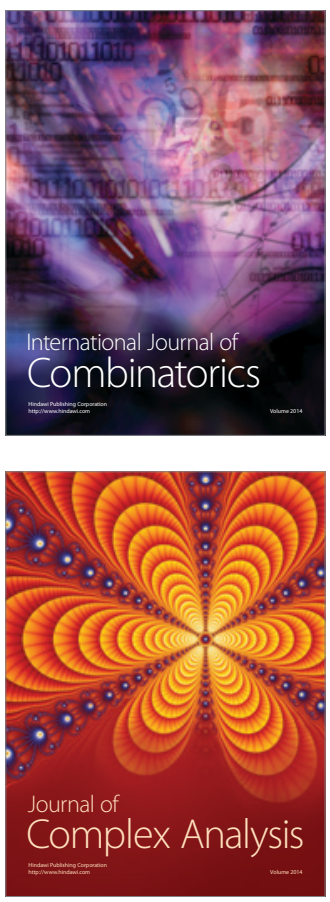

International Journal of

Mathematics and

Mathematical

Sciences
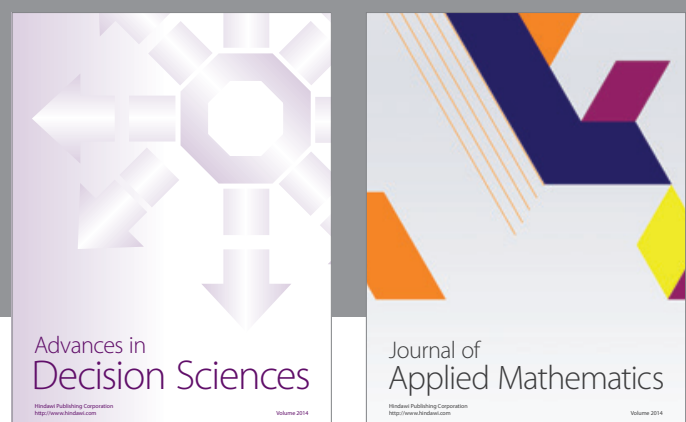

Journal of

Applied Mathematics
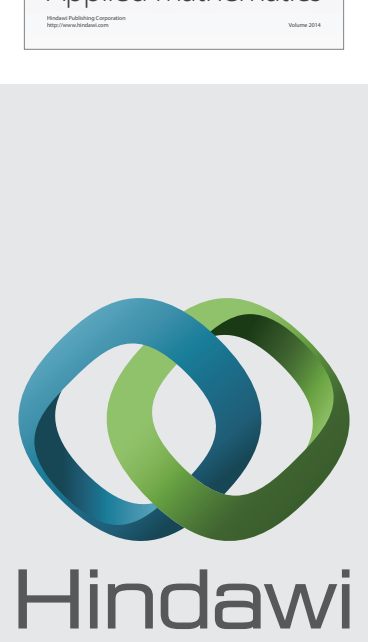

Submit your manuscripts at http://www.hindawi.com
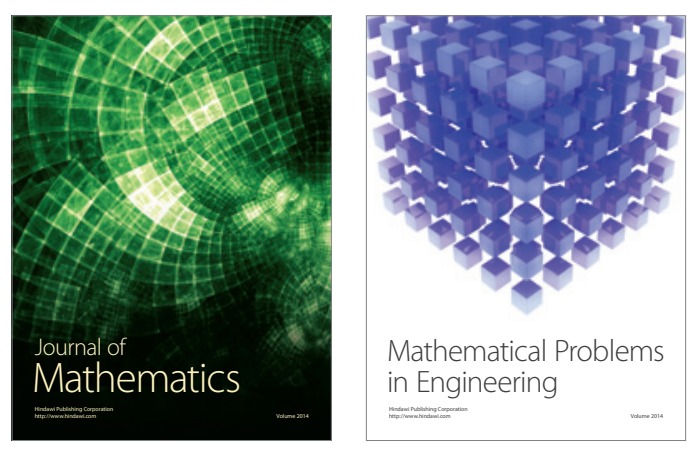

Mathematical Problems in Engineering
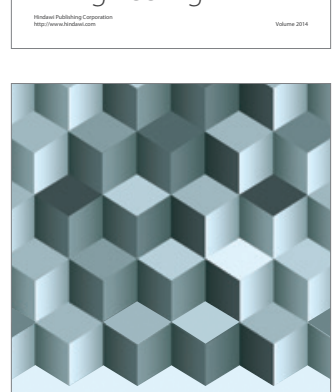

Journal of

Function Spaces
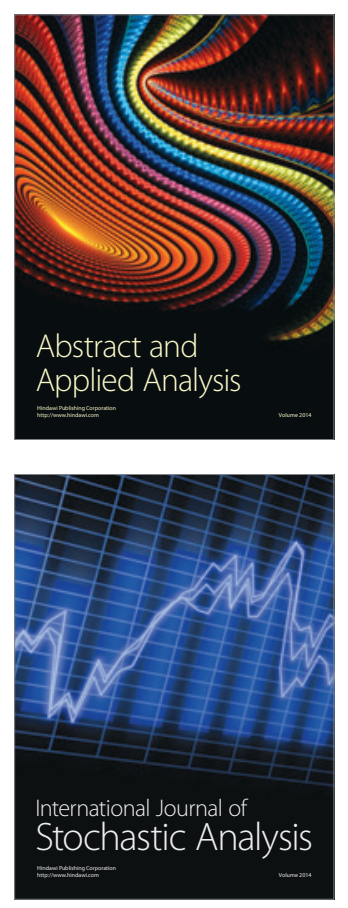

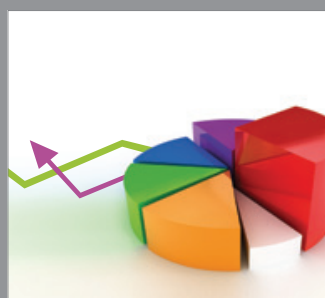

ournal of

Probability and Statistics

Promensencen
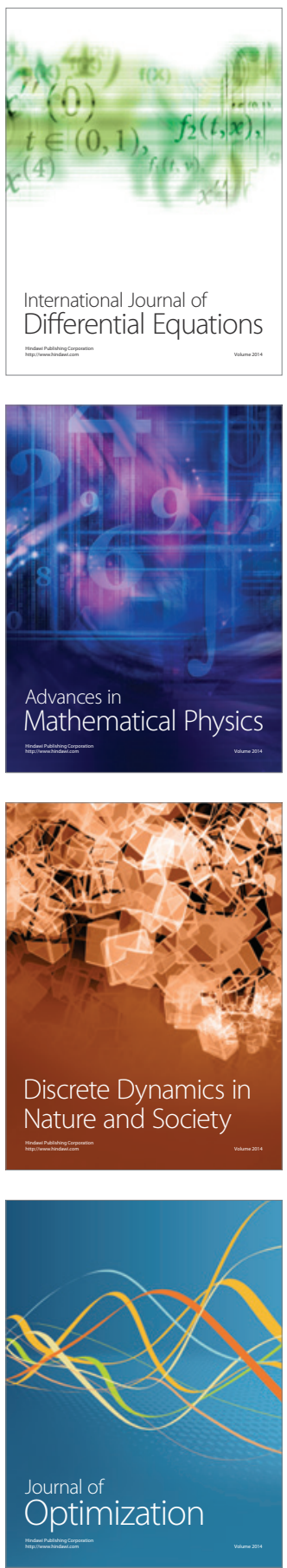